\title{
PERANCANGAN SISTEM INFORMASI AKUNTANSI SIKLUS PENGGAJIAN PADA PERUSAHAAN RETAIL
}

\author{
Sugiarto Hartono ${ }^{1}$, Rouly Doharma ${ }^{2}$ \\ ${ }^{1}$ Program Sistem Informasi, Program Studi Sistem Informasi, Universitas Bina Nusantara \\ Jln. K.H. Syahdan No. 9, Palmerah, Jakarta Barat, 11480 \\ E-mail: shartono@binus.edu \\ ${ }^{2}$ Program Sistem Informasi, Program Studi Sistem Informasi, STMIK WIDURI \\ Jln. Palmerah Barat No 353, Jakarta, 12210 \\ E-mail: rouly.doharma@gmail.com
}

\begin{abstract}
ABSTRAKSI
Tujuan dari penelitian ini adalah untuk mengidentifikasi. menganalisis serta merancang sebuah sistem informasi akuntansi penggajian untuk mendukung proses penggajian pada perusahaan retail. Metode perancangan yang digunakan adalah metode Object Oriented Analysis and Design (OOAD) yang mengacu pada permodelan. Untuk menggali informasi mengenai proses bisnis yang berjalan, maka dilakukan beberapa tahap seperti survei, wawancara dan identifikasi masalah. Analisis dilakukan berdasarkan proses penggajian yang saat ini berjalan, selanjutnya hasil analisis dituangkan dalam perancangan sistem informasi akuntasi penggajian berupa aplikasi web yang dapat membantu kegiatan absensi, izin/cuti, lembur, pinjaman dan penggajian, khususnya pendokumentasian dan penyimpanan data yang terintegrasi sehingga membantu mempercepat proses perhitungan gaji karyawan.
\end{abstract}

Kata Kunci: sistem informasi akuntansi, siklus penggajian, OOAD, perusahaan retail 


\section{PENDAHULUAN}

Internet merupakan salah satu bentuk perkembangan teknologi. Dalam penelitian mengenai profil pengguna internet di Indonesia tahun 2012, APJII melaporkan penetrasi pengguna internet di Indonesia adalah $24,23 \%$. Sementara survey di tahun 2014 menunjukkan penetrasi pengguna internet di Indonesia adalah $34.9 \%$ (APJII, 2014). Hal ini menunjukan bahwa perkembangan teknologi di era globalisasi ini sudah semakin cepat dan aktivitas-aktivitas menjadi lebih mudah dengan adanya IT. (Noerlina, Johan, dan Yoswara, 2011)

Dengan adanya kebutuhan teknologi, semakin banyak perusahaan yang berlomba-lomba untuk menjadi yang terbaik dalam bidangnya. Maka dari itu, diperlukan sistem yang dapat membantu pekerjaan dengan memanfaatkan teknologi yang ada. Teknologi digital memiliki peran yang semakin penting dalam kehidupan karyawan dan human resource management (HRM) yang terpengaruh dalam berbagai cara. Perubahan pada HRM akan berdampak kepada tenaga kerja, khususnya dengan perubahan penggunaan teknologi dalam menjalankan kegiatan HRM. (Suryanto, 2011; Parry \& Strohmeier, 2014)

Selain mengolah informasi, tenaga kerja atau sumber daya manusia juga merupakan hal yang penting dan memerlukan perhatian khusus dalam menjalankan sebuah bisnis. Semakin besar suatu perusahaan, semakin besar pula jumlah tenaga kerja yang dibutuhkan di dalamnya. Peran tenaga kerja akan sangat berpengaruh karena mereka yang bertugas dalam mengelola sumber daya lainnya yang dapat mendukung kegiatan operasional agar tercapainya tujuan perusahaan. Hameed dan Waheed (2011:224) menyatakan bahwa karyawan merupakan elemen kunci dari sebuah organisasi. Kesuksesan atau kegagalan organisasi tergantung dengan kinerja aryawan. Untuk itu, hak para pekerja tersebut merupakan hal yang penting untuk dipenuhi, dalam hal ini berupa gaji yang merupakan salah satu biaya tenaga kerja yang dikeluarkan perusahaan dan memerlukan ketelitian dalam perhitungan serta pembayarannya.

Sistem penggajian bermanfaat untuk menyimpan data karyawan secara lebih akurat dan mudah diakses, serta mempercepat proses perhitungan gaji yang akurat dan pembayaran gaji tepat waktu. Untuk mendapatkan

manfaat tersebut, maka sebuah perusahaan membutuhkan sistem penggajian yang terkomputerisasi dan terintegrasi yang dapat menghubungkan data pribadi karyawan dengan kumpulan data terkait penggajian karyawan dengan cara yang lebih cepat dan efisien. (Singh, 2014; Kaur \& Grover, 2012)

Sistem absensi di salah satu perusahaan retail yang bergerak di bidang penjualan peralatan computer saat ini telah menggunakan mesin biometrik berupa pengenalan sidik jari yang disebut juga fingerprint untuk mencatat kehadiran setiap individu atau pekerja di perusahaan. Namun perusahaan masih bermasalah karena hasil yang dikeluarkan dari mesin biometrik tersebut tidak terintegrasi dengan proses penggajian. Sistem absensi tersebut juga tidak dapat menyimpan data cuti atau izin karyawan sehingga membutuhkan waktu lebih untuk menghitung jumlah kehadiran karyawan.

Proses perhitungan gaji, cuti, dan lembur untuk setiap karyawan belum menggunakan sistem yang terintegrasi, sehingga perusahaan mengalami kesulitan dalam memproses penggajian karyawan, membutuhkan waktu cukup lama dan memiliki risiko yang cukup besar terhadap tingkat kesalahan manusia dalam prosesnya. Dengan menerapkan sistem informasi akuntansi penggajian ini, perusahaan dapat menyelesaikan masalah yang ada dan sangat menguntungkan perusahaan karena menurunkan risiko salah saji, penipuan dan kesalahan yang disebabkan oleh manusia, khususnya dalam proses penggajian.

Dalam mengembangkan sistem informasi akuntansi penggajian ini digunakan metode Object Oriented Analysis and Design. Ang dan Brahmawong (2009:39.1) menyatakan bahwa object oriented menggambarkan sistem sebagai objek, dimana lebih dekat dengan dunia nyata dibandingkan dengan pendekatan struktural. Pendekatan ini dipilih karena karakteristik yang mencerminkan sistem sebagai objek yang lebih dimengerti. Manfaat lain dari metode tersebut adalah memberikan pemahaman lebih baik terhadap user requirement, kerapian dan fleksibilitas desain, penjelasan sistem konsisten, memfasilitasi data abstraction \& information hiding, penggunaan kembali perangkat lunak, perawatan mudah, dan dapat diimplementasikan dengan fleksibel. (Sathiyaraj, Yadav, dan Prabhakar, 2012)

Berdasarkan latar belakang tersebut, perusahaan membutuhkan adanya sistem informasi akuntansi penggajian yang terkomputerisasi. Diharapkan dengan adanya sistem tersebut, perusahaan dapat menghemat waktu dan tenaga, serta dapat mengalokasikan sumber daya tersebut ke bidang atau departemen yang lain untuk membantu perusahaan berkembang. Oleh karena itu, perusahaan membutuhkan sebuah sistem informasi penggajian yang dirancang dengan menggunakan pendekatan Object-Oriented dan diharapkan dapat mengatasi permasalahan yang terjadi.

\section{METODE PENELITIAN}

Metodologi yang digunakan dalam penulisan skripsi ini adalah sebagai berikut :

1. Metode Pengumpulan Data 
a. Wawancara

Melakukan tanya jawab dengan owner mengenai proses penggajian dalam perusahaan.

\section{b. Dokumentasi}

Meminta contoh dokumen yang digunakan selama proses penggajian.

\section{c. Studi Pustaka}

Mencari serta mempelajari bahan, materi dan teori pendukung yang terkait sistem informasi akuntansi penggajian dari berbagai sumber.

\section{Metode Analisis dan Perancangan}

Menggunakan pendekatan berorientasi objek menurut Satzinger, Jackson dan Burd yaitu Object Oriented Analysis and Design (OOAD) yang terdiri dari beberapa tahapan yaitu :

\section{a. Inception Phase}

Tahapan ini merupakan tahapan paling awal, dimana aktivitas penilaian terhadap kebutuhan sebuah sistem dilakukan. Fase ini dilakukan dengan mengumpulkan data yang berkaitan dengan proses penggajian, menganalisa struktur organisasi, visi dan misi perusahaan, serta menganalisa proses penggajian yang sedang berjalan di dalam perusahaan.

\section{b. Elaboration Phase}

Tujuan dari tahap ini adalah untuk mendapatkan gambaran umum kebutuhan, persyaratan, dan fungsifungsi utama perangkat lunak. Hal ini penting untuk mengetahui secara lebih baik resiko-resiko proyek, baik meliputi resiko arsitektur perangkat lunak, perencanaan, maupun implementasi. Metode perancangan yang digunakan dalam penyelesaian penelitian menggunakan metode Object Oriented Analysis and Design, yang terdiri dari:

1. Merancang usecase realization

2. Merancang user interface

3. Merancang software architecture

4. Merancang database

5. Merancang system security and control

\section{c. Construction Phase}

Membangun perangkat lunak sesuai dengan rancangan yang telah dibuat pada tahap elaboration hingga siap digunakan serta melanjutkan analisis dan desain secara detail.

6. Metode Pencatatan Jurnal Standar Akuntansi Metode pencatatan jurnal dan standar akuntansi yang digunakan adalah Standar Akuntansi Keuangan untuk Entitas Tanpa Akuntabilitas Publik (SAK-ETAP), dimana dalam penelitian ini SAK-ETAP Bab 23 tentang Imbalan Kerja dijadikan acuan dalam pencatatan jurnal akuntansi. Tujuan dari SAK-ETAP Bab 23 yaitu mengatur akuntansi dan pengungkapan imbalan kerja, dimana perusahaan mengakui liabilitas jika tenaga kerja telah memberikan kinerjanya atau prestasinya kepada perusahaan dan berhak memperoleh imbalan kerja di masa yang akan datang, dan mengakui beban jika perusahaan telah menikmati manfaat ekonomis dari kinerja karyawan dan berhak memperoleh imbalan di masa yang akan datang.

\section{Metode Perhitungan Pajak Penghasilan}

Undang-undang Pajak Penghasilan yang digunakan sebagai acuan untuk menghitung pajak penghasilan karyawan adalah Undang-Undang Republik Indonesia Nomor 36 Tahun 2008 tentang Pajak Penghasilan.

Peraturan Menteri Keuangan Nomor 122/PMK.010/2015, tentang Penghasilan Tidak Kena Pajak (PTKP) menjadi dasar penetapan PTKP karyawan.

\section{HASIL DAN DISKUSI}

Permasalahan yang dihadapi di perusahaan antara lain:

1. Waktu bekerja karyawan

Karyawan di perusahaan tidak bekerja di satu tempat, melainkan di tempat-tempat yang berbeda. Perusahaan hanya memiliki 1 mesin absensi sehingga mengharuskan karyawan untuk melakukan absen terlebih dahulu sebelum mulai bekerja dimana hal tersebut membuat jam kerja yang tercatat dengan yang terjadi tidak sesuai. Hal ini seharusnya tidak boleh terjadi karena dapat merugikan perusahaan maupun karyawan. Dengan menggunakan website untuk melalukan absensi akan meningkatkan keakuratan pencatatan waktu kerja karyawan sehingga mengurangi kemungkian terjadinya kurang atau lebih bayar gaji karyawan dan meningkatkan efisiensi waktu kerja karyawan.

\section{Proses cuti tidak tercatat dengan baik}

Jika ada karyawan yang ingin mengajukan izin/cuti, maka karyawan tersebut hanya perlu menanyakan secara lisan ke atasan mereka apakah mereka diizinkan untuk mengambil izin/cuti atau tidak. Apabila diizinkan, maka atasan dari karyawan yang bersangkutan akan memberitahukan manager keuangan untuk mencatat hal tersebut. Masalah yang mungkin terjadi adalah kelalaian dari atasan yang lupa memberitahu manager keuangan ataupun manager keuangan yang lupa untuk mencatat izin/cuti karyawan tersebut. Pencatatannya juga tidak teratur sehingga memungkinkan terjadinya kehilangan data ataupun otorisasi yang tidak semestinya seperti mengizinkan karyawan yang ternyata telah habis jatah cutinya. Sistem yang terintegrasi akan sangat membantu perusahaan ketika melakukan rekap data absensi dan dapat dengan mudah mengetahui apakah karyawan mereka cuti atau tidak masuk tanpa harus mencari dan mencocokan catatan absensi dengan catatan izin/cuti yang mungkin tercecer atau bertumpuk. Sistem juga dapat mengendalikan perizinan cuti karyawan dengan 
baik karena karyawan tidak dapat mengajukan izin/cuti apabila jatah cutinya sudah habis.

\section{Proses lembur tidak tercatat}

Dalam waktu kerja sehari-hari, perusahaan tidak memberlakukan lembur karyawan. Lembur hanya bisa terjadi apabila terdapat kebutuhan khusus yang dilakukan diluar jam kerja, biasanya hanya terjadi di bagian gudang, ketika melakukan stock opname. Pembayaran lembur dilakukan di hari itu juga, setelah karyawan selesai melakukan lembur dan tidak ada pencatatan untuk itu. Maka itu penggunaan sistem dapat membantu perusahaan dalam proses lembur dengan mencatat dan menyimpan data lembur, serta meminimalisir terjadinya fraud dalam pembayaran uang lembur yang dapat merugikan perusahaan maupun karyawan.

\section{Keterlambatan dalam penggajian}

Tiap bulannya karyawan akan menerima gaji, namun karena proses perhitungan gaji yang memakan waktu 2

- 3 hari, pembayaran gaji karyawan menjadi terlambat sehingga merugikan karyawan. Hal ini terjadi karena data-data yang dibutuhkan untuk menghitung gaji karyawan seperti absensi dan izin/cuti karyawan tidak lengkap dan tidak sesuai, terdapat data yang hilang, karyawan yang lupa melakukan absensi dan perhitungan gaji karyawan masih dilakukan satu per satu secara manual. Diperlukan sistem yang dapat melakukan perhitungan gaji karyawan secara cepat dan tepat sehingga masalah dalam waktu pemberian gaji yang selama ini dirasa merugikan bagi karyawan dapat terselesaikan. Perhitungan gaji menggunakan sistem yang cepat dan akurat juga menguntungkan perusahaan karena mengurangi waktu kerja untuk menghitung gaji karyawan yang cukup banyak.

\section{Kurangnya kontrol update master data}

Ketika karyawan melamar dan diterima untuk bekerja, maka perusahaan akan menyimpan data karyawan yang berupa CV dan fotokopi KTP, sehingga jika terdapat perubahan data diri karyawan akan sulit bagi perusahaan untuk mengubah data tersebut. Hal ini mengakibatkan kurangnya perhatian untuk melakukan kontrol terhadap data tersebut dan perusahaan akan mengalami kerugian secara tidak langsung karena hanya memiliki data karyawan yang lama dan mungkin tidak lagi valid.

Alangkah baiknya jika disimpan dalam database dan terdapat sistem yang memudahkan perusahaan untuk menyimpan, menambah, maupun mengubah data tersebut sehingga perusahaan dapat mempertahankan keakuratan data terutama master data yang dimiliki.

Berikut adalah usecase untuk sistem yang diusulkan:

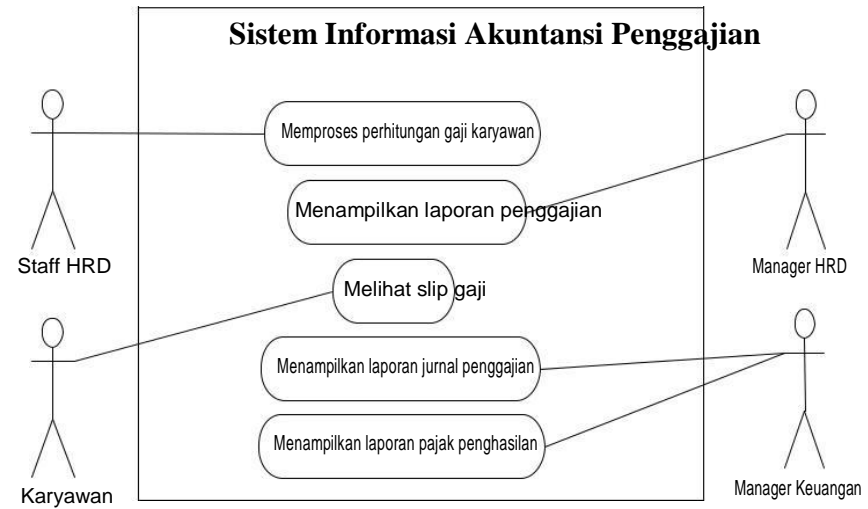

Gambar 1. Use Case Diagram untuk sistem informasi akuntansi penggajian

Tampilan antarmuka untuk pemrosesan laporan penggajian adalah:

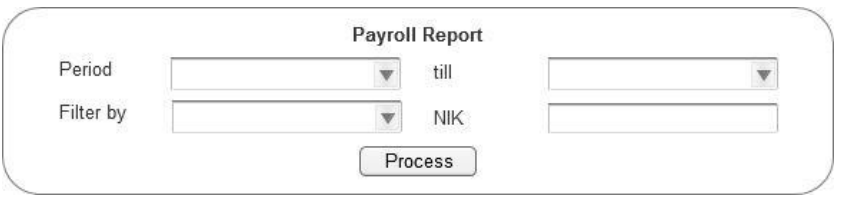

Gambar 2. Tampilan user interface untuk sistem informasi akuntansi penggajian

Output dari sistem penggajian di perusahaan retail yang disarankan adalah sebagai berikut:

\begin{tabular}{|c|c|c|c|c|c|c|}
\hline \multicolumn{2}{|c|}{ Payroll Report } & \multirow{2}{*}{\multicolumn{3}{|c|}{ : June 2016}} & \multirow[b]{2}{*}{ Print Date } & \multirow[b]{2}{*}{$7 / 112016$} \\
\hline & & & & & & \\
\hline No. & NIIK & Name & Position & Account Number & Account Name & Net Pay \\
\hline 1 & 100001 & Alice & HRManager & 31203912093 & Alice Wall & \\
\hline 2 & 100002 & Barney & HR Staff & 10283749219 & Barney Dee & 3350 \\
\hline 3 & 100003 & Cecil & HRStaff & 45282321210 & Cecil Lu & 3600 \\
\hline 4 & 100004 & Dwine & HRStaff & 10283749113 & Dwine Rook & 3350 \\
\hline 5 & 100005 & Einne & HRStaff & 21283749210 & Einne Salt & 35000 \\
\hline
\end{tabular}

Gambar 3. System Output untuk sistem informasi akuntansi penggajian

Untuk menjaga kontrol aplikasi maka diperlukan beberapa teknik yaitu:

a. Nomor dokumen berurut dan auto generate Pengendalian dengan penggunaan nomor berurut yang dibuat secara otomatis dapat meminimalisir terjadinya human error dan praktik kecurangan.

b. Pemeriksaan kelengkapan dan validitas

Kelengkapan dan validitas data yang diinput diperiksa sebelum dimasukan ke dalam database untuk menjaga agar tidak terjadi masalah ketika sistem dijalankan serta memastikan data yang diperlukan tersedia dan dapat diandalkan.

\section{c. Penggunaan message box}

Beberapa message box dirancang untuk memberikan konfirmasi dan informasi kepada user. Salah satunya ketika karyawan melakukan absensi masuk dan keluar, message box berisi NIK, nama, tanggal dan waktu karyawan akan muncul sebagai konfirmasi pencatatan absensi. 


\section{d. Processing control}

Data yang masuk diolah menggunakan sistem sehingga meminimalisir kesalahan yang mungkin terjadi dalam pemrosesan data seperti menghitung gaji karyawan.

\section{e. Log Activity}

Sistem memiliki pencatatan untuk aktivitas-aktivitas yang dilakukan user di dalam sistem yang berpengaruh terhadap data di dalam database seperti insert dan update.

\section{KESIMPULAN}

Berdasarkan hasil analisis masalah dari prosedur sistem berjalan dan perancangan sistem informasi akuntansi penggajian yang diusulkan, maka dapat disimpulkan bahwa:

1. Karyawan membutuhkan waktu dari lokasi mesin fingerprint ke lokasi tempat kerja karyawan. Hal ini berdampak terhadap realisasi waktu kerja karyawan menjadi tidak sesuai dengan waktu yang dicatat oleh mesin fingerprint dikarenakan mesin fingerprint yang terbatas. Dengan adanya fitur absensi dalam sistem informasi akuntansi penggajian berbasis web, pencatatan jam kerja karyawan akan menjadi lebih akurat dan memudahkan karyawan untuk melakukan absensi di lokasi tempat kerja karyawan.

2. Sistem informasi yang terintegrasi dapat membantu perusahaan menyelesaikan permasalahan terkait dengan perizinan dengan baik seperti membatasi pengajuan cuti dengan mengecek jatah cuti karyawan sebelum mengajukan izin/cuti dan menyimpan data izin/cuti dengan lebih baik di database untuk mengurangi kemungkinan terjadi kehilangan data karena tercecer.

3. Terkait dengan proses lembur yang tidak tercatat sehingga mengakibatkan kemungkinan terjadinya fraud dalam pembayaran lembur karyawan, maka diusulkan untuk dibuatkan sebuah sistem yang terkomputerisasi yang didalamnya terdapat form yang digunakan untuk mencatat lembur dan lembur akan dibayarkan bersamaan dengan gaji pada akhir bulan.

4. Proses perhitungan gaji yang dilakukan secara otomatis di dalam sistem penggajian yang terintegrasi akan membantu menyelesaikan masalah keterlambatan dalam pembayaran gaji karyawan.

5. Sistem yang dirancang akan membantu dalam penyimpanan data, pencarian data, penambahan data dan pengubahan data lebih mudah dengan fitur master sebagai akses sehingga masalah kurangnya pengendalian terhadap master data dapat diatasi dengan baik.

\section{DAFTAR PUSTAKA}

Asosiasi Pengguna Jasa Internet Indonesia (APJII). (2014). Profil Pengguna Internet Indonesia 2014. Retrieved April 20, 2016, from APJII: https://apjii.or.id/downfile/file/PROFILPENGGU NAINTERNETINDONESIA2014.pdf

Hameed, A., \& Waheed, A. (2011). Employee Development and Its Affect on Employee Performance A Conceptual Framework. International Journal of Business and Social Science, 224-229.

Kaur, P., \& Grover, D. D. (2012). Computer Based Payroll System Implementation For E-Governance at Punjab Agricultural University. International Journal of Engineering Research and Development , 55-60.

Kementerian Keuangan RI. (2015). 122 PMK.010 2015Per.Pdf. Retrieved July 18, 2016, from Kementerian Keuangan RI: http://www.jdih.kemenkeu.go.id/fulltext/2015/122 $\sim$ PMK.010 2015Per.pdf

Noerlina, Johan, \& Yoswara, Y. (2011). Analysis and Design: Accounting Information System in Purchasing and Supplying. CommIT , 18-20.

Parry, E., \& Strohmeier, S. (2014). HRM in the digital age - digital changes and challenges of the HR profession. Employee Relation, 36 (4).

Satzinger, J. W., Jackson, R. B., \& Burd, S. D. (2005). Object-Oriented Analysis and Design with the Unified Process. Boston, USA: Course Technology Cengage Learning.

Singh, G. (2014). Implementation and Development of a Proposed Payroll System. International Journal of Research , 954-965.

Suryanto. (2011). Design and Analysis: Payroll of Accounting Information System. CommIT , 24-26.

Weygandt, J., Kimmel, P., \& Kieso, D. (2011). Financial Accounting IFRS Edition. United States of America: John Wiley \& Sons, Inc. 